\title{
АНАЛИЗ ВЛИЯНИЯ ПРОИЗВОДСТВЕННОГО ЦИКЛА РАБОТЫ ПОГРУЗОЧНО-ДОСТАВОЧНОЙ МАШИНЫ В ОЧИСТНОЙ ТУПИКОВОЙ КАМЕРЕ НА ЭФФЕКТИВНОСТЬ ПРОВЕТРИВАНИЯ
}

\author{
Е.В. Накаряков, Е.Л. Гришин \\ Горный институт УрО РАН, г. Пермь
}

\begin{abstract}
Аннотация: В работе представлены результаты математического моделирования условий проветривания протяженных тупиковых очистных камер при работе в них погрузочно-доставочных машин с двигателем внутреннего сгорания. Произведена оценка влияния производственного цикла работы погрузочно-доставочной машины на процесс выноса ядовитых примесей рудничного воздуха из пространства очистной камеры на рабочее место горнорабочего.

Ключевые слова: тупиковые выработки, двигатель внутреннего сгорания, математическое моделирование, ядовитые газы, вентилятор местного проветривания.
\end{abstract}

\section{Введение}

В российской нормативной документации [1] отсутствуют требования по проветриванию тупиковых камерообразных выработок, образующихся за счет расширения нарезной выработки до камерообразной при обратном порядке отработки. В связи с недостаточностью требований нормативной документации возникает необходимость исследования эффективности выноса ядовитых примесей выхлопных газов погрузочно доставочных машин (далее по тексту - ПДМ) из камерного пространства.

Очистное пространство камерообразной выработки не имеет крепления, существует опасность нахождения внутри камерного пространства. Детальные экспериментальные исследования газовыделений в очистном пространстве камеры и его проветривания невозможны ввиду запрета нахождения горнорабочих внутри камерного пространства, а также невозможности одновременного выполнения производственных процессов по добыче полезных ископаемых и экспериментов. Разумной альтернативой натурных исследований в данном случае является численное моделирование [2], с помощью которого становится возможным исследовать динамику вредных компонентов выхлопных газов ПДМ и проветривание очистного пространства камеры. Целью исследования является разработка методики безопасного проветривания данного вида горных выработок в процессе отгрузки руды. Для достижения поставленной цели решается ряд задач:

1) разработка и верификация математической модели проветривания тупиковых очистных камер большого сечения;

2) определение параметров безопасного проветривания протяженных тупиковых очистных камер большого сечения при отгрузке руды ПДМ с двигателем внутреннего сгорания;

3) определение зависимостей изменения концентраций вредных компонентов выхлопных газов в рабочей зоне от цикла работы ПДМ;

4) оценка влияния геометрических параметров очистного пространства камеры и нарезной выработки на процесс выноса газа из пространства камеры;

5) оценка влияния аэродинамических параметров проветривания очистной камеры на процесс выноса газа из пространства камеры;

6) оценка влияния цикла работы ПДМ на процесс выноса газа из пространства камеры;

7) определение максимально возможной длины тупиковой камеры.

Ряд задач решен в предыдущих исследованиях [3].

В данной работе приведены результаты исследований влияния производственного цикла работы ПДМ в пространстве очистной камеры. $\mathrm{C}$ целью оценки максимального 
времени нахождения ПДМ в камере и минимального времени ее отсутствия произведено математическое моделирование различных производственных циклов на модели обобщенной очистной камеры.

\section{Модель}

В модуле SpaceClaim программного комплекса ANSYS построена модель обобщенной очистной камеры.

Геометрические параметры обобщенной модели очистной камеры, использованные при численном моделировании проветривания камеры при работе в ней ПДМ, представлены на рисунке 1.

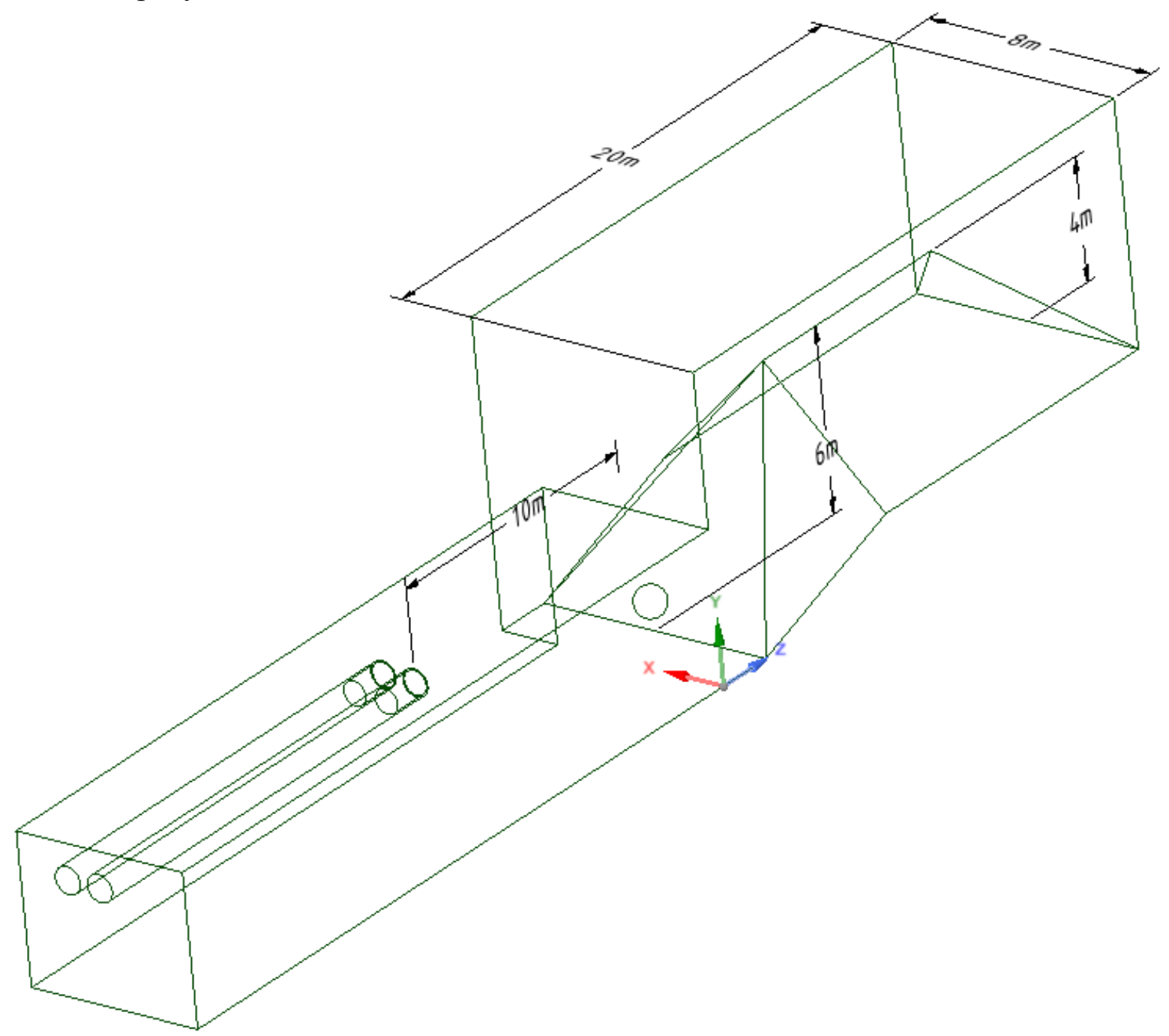

Рис. 2. Геометрическая модель очистной камеры и разрезной выработки

Параметры численной модели соответствуют ранее описанным в работах $[3,6]$. Для определения поля скоростей воздуха используются усредненные по Рейнольдсу уравнения Навье-Стокса $[7,8]$. Для определения кинетической энергии турбулентности использована стандартная $k$ - $\varepsilon$ модель турбулентности с масштабируемыми пристеночными функциями $[9,10]$. Течение воздуха повсеместно происходит в режиме развитой турбулентности. На выходе из вентиляционного става задается средняя скорость воздуха по сечению, интенсивность турбулентности $I_{t u r b}=2 \%$, масштаб вихрей турбулентности $l_{t u r b}=0,2$ м. Воздушный поток, омывая очистную камеру и разрезной штрек, покидает расчетную область через поверхность, на которой задается нулевое статическое 
давление, интенсивность турбулентности $I_{t u r b}=2 \%$, масштаб вихрей турбулентности $l_{\text {turb }}=0,2$ м. На стенках горных выработок задается «прилипание» потока. Расчет пограничного слоя осуществляется с учетом повышенной шероховатости стенок горных выработок. Величина шероховатости стенок выработок равна 0,03 м. Количество воздуха, поступающего на проветривание по двум вентиляционным трубопроводам диаметром $0,8 \mathrm{M}$, составляет $-15 \mathrm{~m} / \mathrm{c}$, величина отставания вентиляционных трубопроводов от устья очистного пространства камеры - 10 м. Исследуемая расчетная область разбивается на конечные элементы, а решаемая система математических уравнений записывается в конечно-объемной форме. Неизвестными параметрами задачи в данном случае становятся значения скоростей воздуха в узлах конечных объемов и значения давлений воздуха.

Для ускорения расчета проводилось распараллеливание вычислений между 8-ю ядрами центрального процессора с использованием платформы MPI Local Parallel.

В рамках исследования произведена оценка зависимости возрастания средней концентрации газов (в пересчете на условный $\mathrm{CO}$ ) на выходе из разрезной выработки от времени работы ПДМ в камере, а также зависимости снижения средней концентрации газов на выходе из разрезной выработки от времени отсутствия ПДМ в камере.

Исследуемые производственные циклы («время работы/время отсутствия»):

- «5/1»,

- «5/4»,

- «7/1»,

- «7/2»,

- $\ll 7 / 4 »$,

- $« 7 / 6 »$,

- «9/4».

\section{Результаты}

По результатам моделирования получены поля концентраций условного СО по сечению выхода из расчетной области. Результаты представлены в виде графиков зависимости средней концентрации условного СО (\% по объему) на выходе из разрезной выработки от времени (мин) на рисунке 3 .

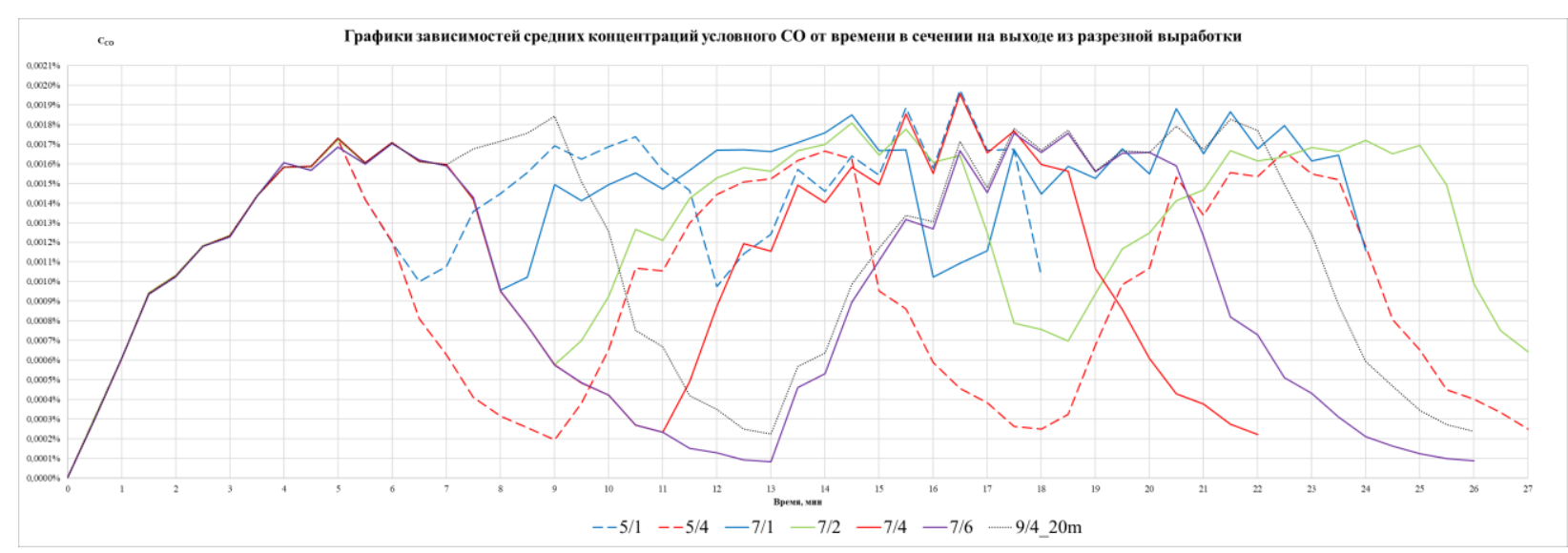

Рис. 3. Графики зависимости средней концентрации условного СО на выходе из разрезной выработки от времени при различных производственных циклах работы ПДМ

Из рисунка 2 видно, что зависимость возрастания/снижения средней концентрации газов (в пересчете на условный $\mathrm{CO}$ ) на выходе из разрезной выработки от времени работы/отсутствия ПДМ в камере имеет экспоненциальную зависимость при различных 
производственных циклах на каждом из циклов работы ПДМ, также с увеличением времени работы ПДМ в камере концентрация условного СО достигает асимптотического максимума.

\section{Выводы}

Возрастание концентраций вредных компонентов выхлопных газов ПДМ в разрезной выработке при работе ПДМ в очистном пространстве имеет экспоненциальный характер.

Как максимум к третьему циклу работы ПДМ по отгрузке полезного ископаемого максимальное значение концентрации вредных компонентов выхлопных газов ПДМ в сечении разрезной выработки достигает асимптотического занчения.

При моделировании работы ПДМ по отгрузке полезного ископаемого из пространства очистной камеры наблюдаются кратковременные превышения предельно-допустимого значения концентрации $\mathrm{CO}(0,0017 \%$ по объему) в сечении разрезной выработки. Это говорит о необходимости предварительного аналитического определения максимального времени нахождения ПДМ в очистном пространстве камеры при производстве отгрузки полезного ископаемого.

Исследование выполнено при финансовой поддержке Российского научного фонда в рамках проекта № 19-77-30008.

\section{БИБЛИОГРАФИЧЕСКИЙ СПИСОК}

1. Федеральные нормы и правила в области промышленной безопасности «Правила безопасности при ведении горных работ и переработке твердых полезных ископаемых»: утв. 11.12.2013, № 32935. (с изм. на 21.11.2018 г. Редакция, действующая с 17.03.2019 г.) - Текст электронный // Консорциум КОДЕКС. Электронный фонд правовой и нормативно-технической документации: офиц. сайт. URL: http://docs.cntd.ru/document/499066482 (Дата обращения 25.08.2020)

2. Качурин Н.М., Стась Г.В., Мохначук И.И., Поздеев А.А. Аэрогазодинамика очистных участков шахт и рудников // Проблемы безопасности и эффективности освоения георесурсов в современных условиях: материалы науч.-практ. конф., посвящ. 25-летию Горн. ин-та УрО РАН и 75-летию основателя и первого директора ин-та чл.-корр. РАН А.Е. Красноштейна / ГИ УрО РАН. - Пермь, 2014. - С. 381386.

3. Накаряков Е.В. Анализ влияния геометрических параметров поперечного сечения очистной тупиковой камеры на эффективность ее проветривания // Горное эхо. - 2019. - Т. 76, № 3. - С. 76-79. DOI: 10.7242/echo.2019.3.21.

4. Левин Л.Ю., Исаевич А.Г., Семин М.А., Газизуллин Р.Р. Исследование динамики пылевоздушной смеси при проветривании тупиковой выработки в процессе работы комбайновых комплексов // Горн. журн. - 2015. - № 1. - С. 72-75. DOI: 10.17580/gzh.2015.01.13.

5. Казаков Б.П., Семин М.А., Мальцев С.В. Математическое моделирование проветривания панелей гипсовой шахты эжекторными установками // Изв. Тульского гос. ун-та. Науки о Земле. - 2018. - № 3. - С. 245-255

6. Колесов Е.В. Обоснование последовательного проветривания рабочих зон нескольких тупиковых выработок // Стратегия и процессы освоения георесурсов: сб. науч. тр. Вып. 16 / ГИ УрО РАН. Пермь, 2018. - С. 291-295. DOI: 10.7242/gdsp.2018.16.78.

7. Torno S., Torano J., Ulecia M., Allende C. Conventional and numerical models of blasting gas behaviour in auxiliary ventilation of mining headings // Tunnelling and Underground Space Technology. - 2013. - V. 34. - P. 73-81. DOI: 10.1016/j.tust.2012.11.003.

8. Xu G., Luxbacher K.D., Ragab S., Xu J., Ding X. Computational fluid dynamics applied to mining engineering: a review // International Journal of Mining, Reclamation and Environment. - 2017. - V. 31, № 4. - P. 251-275. DOI: 10.1080/17480930.2016.1138570.

9. Hasheminasab F., Bagherpour R., Aminossadati S. M. Numerical simulation of methane distribution in development zones of underground coal mines equipped with auxiliary ventilation // Tunnelling and Underground Space Technology - 2019. — № 89. — P. 68-77.

10. Nel A. J.H., Vosloo J.C., Mathews M.J. Evaluating complex mine ventilation operational changes through simulations // Journal of Energy in Southern Africa - 2018. - V. 29, № 3. - P. 22-32. 